\begin{tabular}{|c|c|} 
Jurnal Ayurveda Medistra \\
ISSN. 2656-3142 | Volume 3 Nomor 2 | Agustus 2021 | pages: 32-36 \\
Avalaible online at http://ojs.stikesmedistra-indonesia.ac.id/
\end{tabular}

\title{
HUBUNGAN PENERAPAN PIJAT PERINEUM UNTUK MENGURANGI RUPTUR PERINEUM SAAT PERSALINAN DI KLINIK PRATAMA RATNA KOMALA TAHUN 2020
}

\author{
Renince Siregar, Maslan Pangaribuan, Syifa Fauziah \\ Program Studi Kebidanan (D3 ) STIKes Medistra Indonesia, renin72gar@gmail.com, 0813-1925-31598
}

\begin{abstract}
Abstrak
Kejadian laserasi perineum perlu dilakukan pencegahan, salah satunya dengan pemijatan perineum. Perineum adalah area kulit antara liang vagina dengan anus (dubur) yang dapat robek ketika melahirkan (Herdiana, 2014). Pijat perineum adalah salah satu cara yang paling kuno dan paling pasti untuk meningkatkan kesehatan aliran darah, elastisitas, dan relaksasi otot otot dasar panggul (Hadiningsih 2014 :155). Penelitian ini bertujuan untuk Mengetahui "Hubungan Penerapan Pijat Perineum Untuk Mengurangi Ruptur Perineum Saat Persalinan di Klinik Pratama Ratna Komala Tahun 2020 ". Populasi yang digunakan dalam penelitian ini adalah seluruh ibu bersalin yang ikut kelas Pijat perineum 50 orang pada periode bulan Mei 2020. Sampel pada penelitian ini adalah ibu bersalin yang mengikuti kelas penerapan pijat perineum diri pada saat penelitian mulai Mei dan ibu bersalin yang memiliki data lengkap dengan metode pengambilan sample menggunakan Teknik total sampling. Hasilnya penelitian ini menujukan bahwa terdapat hubungan Penerapan Pijat Perineum Untuk Mengurangi Ruptur Perineum Saat Persalinan hal ini dapat dilihat dari hasil penelitian nilai $p=$ $0,002$ ( $\mathrm{p}<0,05)$. Diharapkan ibu hamil yang menjelang persalinan mengkuti kelas anenatal penerapan pijat perineum agar dapat proses persalinan dapat berjalan sesuai dengan keadaaan atau masih kondisi baik, dan menguraingi terjadinya rupture perineum atau episiotomy.
\end{abstract}

Kata kunci : ibu bersalin, laserasi perineum, rupture perineum, pijat perineum.

\begin{abstract}
The incidence of perineal lacerations needs to be prevented, one of which is perineal massage. The perineum is the area of skin between the vaginal canal and the anus (anus) which can be torn during childbirth (Herdiana, 2014). Perineal massage is one of the oldest and surest ways to promote healthy blood flow, elasticity, and relaxation of the pelvic floor muscles (Hadiningsih 2014:155). This study aims to determine "the relationship between the application of perineal massage to reduce perineal rupture during labor at the Ratna Komala Primary Clinic in 2020". The population used in this study were all mothers who took part in the perineal massage class 50 people in the period in May 2020. The sample in this study were mothers who took part in the application of self-perineal massage when the study began in May and maternity mothers who had complete data with sampling method using total sampling technique. The results of this study indicate that there is a relationship between the application of perineal massage to reduce perineal rupture during delivery, this can be seen from the results of the study, the value of $p=0.002(p<0.05)$. It is expected that pregnant women who are nearing delivery will take an antenatal class on the application of perineal massage so that the delivery process can run according to the condition or is still in good condition, and reduce the occurrence of perineal rupture or episiotomy.
\end{abstract}

Keywords: maternity, perineal laceration, perineal rupture, perineal massage 


\section{PENDAHULUAN}

Angka Kematian Ibu (AKI) untuk Provinsi Jawa Barat tahun 2014 sebesar 116/100.000 kelahiran hidup, sedangkan Angka Kematian Bayi sebesar 12/1.000 kelahiran hidup. Angka Kematian Ibu merupakan salah satu indikator untuk melihat derajat kesejahteraan perempuan dan target yang telah ditentukan dalam tujuan pembangunan Sustainable Development Goals (SDGs) tujuan kelima yaitu meningkatkan kesehatan ibu diimana target yang akan dicapai sampai tahun 2015 adalah mengurangi resiko sampai $3 / 4$ resiko jumlah kematian ibu atau 102/100.000 kelahiran hidup, maka dari itu upaya untuk mewujudkan target tersebut masih membutuhkan komitmen dan usaha keras yang terus menerus (Kementrian Kesehatan Republik Indonesia (Kemenkes RI), 2015).

Kematian ibu saat kehamilan dan persalinan terjadi karena komplikasi yang berhubungan dengan kehamilan dan persalinan. Kurang lebih 529.000 wanita meninggal akibat dari komplikasi tersebut dan kurang lebih 10 juta wanita mengalami kesakitan dan infeksi.(Walyani, 2015).

Penyebab kematian ibu tersebut adalah perdarahan, eklampsia, partus lama, komplikasi aborsi dan infeksi. Adapun kematian ibu di Indonesia $40 \%$ disebabkan oleh perdarahan post partum. Penyebab perdarahan utama atonia uteri, sedangkan penyebab lain adalah retensio plasenta, sisa plasenta, laserasi/robekan jalan lahir dan kelainan darah. Persentase robekan jalan lahir memiliki angka yang kecil tetapi masalah ini bisa menjadi masalah yang serius dalam kematian maternal.Robekan jalan lahir dapat mengenai vagina, serviks, uterus dan perineum (Saifuddin, 2010). Di seluruh dunia pada tahun 2009 terjadi 2,7 juta kasus robekan (ruptur) perineum pada ibu bersalin. Angka ini diperkirakan mencapai 6,3 juta pada tahun 2020.

Perineum walaupun bukan alat kelamin, namun selalu terlibat dalam proses persalinan. Apabila perineum cukup lunak dan elastis, maka lahirnya kepala tidak mengalami kesukaran.Biasanya perineum robek dan paling sering terjadi ruptur perineum derajat I dan derajat II, sedangkan perineum yang kaku dapat menghambat persalinan kala II yang meningkatkan resiko kematian bayi dan menyebabkan kerusakan kerusakan jalan lahir yang.(Hadiningsih, 2014).

Laserasi perineum merupakan penyebab perdarahan kedua setelah atonia uteri, hal ini sering terjadi pada primigravida karena pada primigravida perineum masih utuh, belum terlewati oleh kepala janin sehingga akan mudah terjadi robekan perineum. Jaringan perineum pada primigravida lebih padat dan lebih resisten daripada multipara. Luka laserasi biasanya ringan tetapi dapat juga terjadi luka yang luas yang dapat menimbulkan perdarahan sehingga membahayakan jiwa ibu (Departemen Kesehatan Republik Indonesia (Depkes RI), 2013).dalam penelitian vitrisia 2017)

Berdasarkan uraian diatas peneliti mempertimbangkan atau tertarik melakukan penelitian tentang " Hubungan Penerapan Pijat Perineum Untuk MengurangiRuptur Perineum" Pada Ibu Bersalin Primipara di Klinik Pratama Ratna Komala Tahun 2020"

\section{METODE}

Penelitian ini merupakan jenis penelitian kuantitatif dengan menggunakan desain penelitian cross sectional, untuk melihat hubungan antara variabel independent dengan variabel dependent, dengan tujuan mengetahui hubungan Penerapan Pijat Perineum untuk mengurangi ruptur perineum saat persalinan di Klinik Pratama Ratna Komala tahun 2020. Populasi yang digunakan dalam penelitian ini adalah seluruh ibu bersalin yang ikut kelas Pijat perineum 50 orang pada periode bulan Mei 2020. Sampel adalah sebagian unit penelitian yang ada dalam populasi penelitian. Pengambilan sampel adalah proses pemilihan sejumlah unit penelitian dari populasi penelitian (Lapau 2015). Sampel pada penelitian ini adalah ibu bersalin yang mengikuti kelas penerapan pijat perineum diri pada saat penelitian mulai Mei dan ibu bersalin yang memiliki data lengkap. Metode pengambilan sample dengan menggunakan metode total sampling.

\section{HASIL}

Table 1

Distribusi Responden Berdasarkan Penerapan Pijat Perineum Pada Ibu Bersalin Di Klinik Pratama Ratna Komala

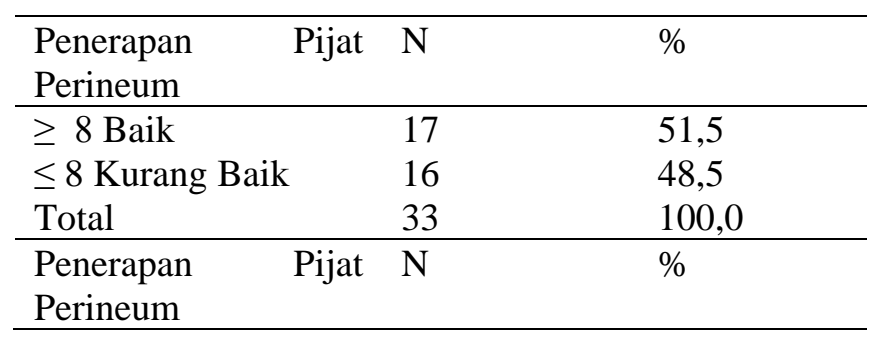

Sumber: Desima Resnawati Manurung 
Berdasarkan tabel 1 diperoleh hasil penelitian ini yang Penerapan Pijat Perineum $\geq 8$ Baik17 responden $(51,5 \%)$, yang $\leq 8$ Kurang Baik berjumlah 16 re6tsponden $(48,5 \%)$.

Table 2

Distribusi responden berdasarkan Kejadian Ruptur Perineum pada ibu bersalin di klinik Pratama ratna komala

\begin{tabular}{lll}
\hline Ruptur & N & $\%$ \\
Perineum & & \\
\hline Ruptur & 11 & 33,3 \\
Tidak Ruptur & 22 & 66,7 \\
Total & 33 & 100,0 \\
\hline Ruptur & N & $\%$ \\
Perineum & & \\
\hline Suber: Desing & Resnati Manurg
\end{tabular}

Sumber : Desima Resnawati Manurung

Berdasarkan tabel 2 diperoleh hasil penelitian ini yang Ruptur Perineum berjumlah 11 responden $(33,3 \%)$, sedangkan yang kategori Tidak Ruptur Perineum berjumlah 22 responden $(66,7 \%)$.

Table 3

Analisis Hubungan Penerapan Pijat Perineum Untuk Mengurangi Rupture Perineum Saat Persalinan Di Klinik Pratama Ratna Komala Tahun 2018

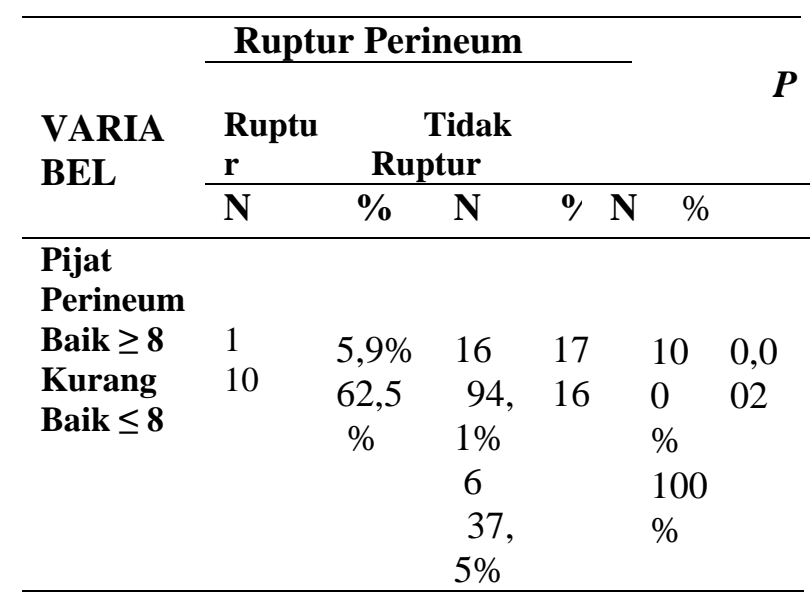

Sumber : olahan data komputerisasi Desima Resnawati

Dari tabel 3 dapat dilihat bahwa ibu bersalin yang melakukan Penerapan pijat perineum yang tidak ada ruptur perineum lebih banyak yaitu sebanyak 16 responden $(94,1 \%)$. Pada ibu bersalin yang tidak melakukan pijat perineum dengan kurang baik ada ruptur perineum sebanyak 10 responden $(62.5 \%)$. Ibu bersalin yang melakukan penerapan pijat perineum dengan baik ada rupture perineum sebanyak sebanyak 1 responden (5,9\%). Ibu bersalin yang tidak melakukan penerapan pijat perineum dengan kurang baik yang tidak ruptur perineum sebanyak 6 responden (37.2\%). Analisis chi-squere digunakan untuk mengetahui hubungan penerapan pijat perineum untuk mengurangi ruptur perineum saat persalinan di Klinik Pratama Ratna Komala tahun 2018. Hasil uji statistic diperoleh nilai $p=0,002(<0,05)$ maka dapat disimpulkan bahwa ada hubungan penerpan pijat perineum untuk mengurangi rupture perineum saat persalinan di Klinik Pratama Ratna Komala tahun 2020.

\section{PEMBAHASAN}

Hasil penelitian menujukan bahwa dari 33 responden mayoritas responden yang melakukan pijat perineum sebanyak frekuensi $\geq 8$ kali yaitu 17 responden atau $(51,5 \%)$. Hal ini responden dapat melakukan pijat perineum sering mungkin dikarenakan dilakuan pagi dan sore sebelum mandi, dan sisanya yang tidak melakukan pijat perineum frekuensi $\leq 8$ sebanyak 16 responden atau $(21,5 \%)$. Hal ini dikarenakan responden tidak melakukan pijat perineum ibu merasakan males dan tidak kenyamanan saat melakukan pijat perineum.

Pijat perineum merupakan salah satu mekanisme koping bagi ibu sehingga ibu berada dalam kenyamanan. Kondisi ini menye babkan perineum menjadi elastis. Ditinjau dari segi psikologi pijat perineum menimbulkan persaan senang dan nyaman sehingga dapat menurunkan kekhawatiran, ketakutan menghadapi persalinan serta dapat menurunkan nyeri hal ini disebabkan karena pijat perineum dapta meningkatkan endorphin sehingga ibu hamil mengalami ketenangan dan rileks sehingga perineum menjadi elastis (Aprilia,2010).

Penelitian diatas sejalan dengan penelitian pernah dilakukan oleh Savitri, dkk (2014) yang berjudul "Pengaruh Pemijatan Perineum pada Primigravida terhadap Kejadian Laserasi Perineum saat Persalinan di Bidan Praktek Mandiri di Kota Bengkulu Tahun 2014" dengan 28 sampel ibu primigravida usia kehamilan 36 minggu yang terdiri dari 14 orang kelompok intervensi dan 14 orang kelompok kontrol. Data dianalisis dengan uji Chi Square. Kejadian laserasi perineum pada kelompok intervensi setelah dilakukan pemijitan perineum hanya 21,4\% sementara pada kelompok kontrol 71,4\%. Hasil penelitian membuktikan bahwa ada 
pengaruh pemijatan perineum pada primigravida terhadap kejadian laserasi perineum dengan nilai $(\mathrm{p}<0,05)$.

Hasil penelitian ini bahwa sebagian besar responden sebagian besar responden mengalami ruptur perineum yaitu sebanyak 11 responden $(33,3 \%)$ dan sisanya 22 responden $(66,7 \%)$ tidak ruptur perineum. Dari 11 responden yang rupture perineum5 diantaranya factor terjadinya episiotomy dan 3 lainnya dari factor martenal atau factor bayi besar, sisanya 4 responden karena factor primi dan sisanya 22 responden .

Ruptur perineum (jalan lahir ) terjadi pada hampir semua persalinan pertama tidak dan tidak jarang juga pada persalinan berikutnya. Ruptur ini dapat dihadirkan atau dikurangi dengan menjaga jangan sampai dasar panggul dilalui oleh kepala janin dengan cepat. Sebaliknya kepala janin yang akan lahir jangan ditahan terlampau kuat dan lama, karena akan menyebabkan asfiksia dan perdarahan dalam tengkorak janin, dan melemahkan otot - otot dan fasia pada dasar panggul karena direngangkan terlalu lama.Ruptur perineum umumnya terjadi di garis tengah dan bisa menjadi luas apabila kepala janin terlalu cepat, sudut arkus pubis lebih kecil daripada biasa sehingga kepala janin terpaksa lahir lebih ke belakang daripada biasa, kepala janin melewati pintu bawah panggul dengan ukuran yang lebih besar daripada sirkumferensia suboksipitobregmatika, atau anak dilahirkan dengan pembedahan vaginal. (Sari, 2014).

Hasil uji bivariat yaitu hasil analisis bivariat hubungan penerapan pijat perineum untuk mengurangi Ruptur perineum diKlinik Pratama Ratna Komala Tahun 2018, diperoleh pvalue sebesar 0,002 . Nilai ini jika dibandingkan dengan harga $\alpha=0,05$ maka pvalue $<0,05$ yang berarti bahwa ada hubungan penerapan pijat perineum untuk mengurangi rupture perinrum di Klinik pratama Ratna Komala Tahun 2018.

Hal ini sejalan dengan teori yang diungkapkan oleh Mongan (2007) bahwa pijat perineum ini akan membantu melunakkan jaringan perineum sehingga jaringan tersebut akan membuka tanpa resistensi saat persalinan, untuk mempermudah lewatnya bayi. Pemijatan perineum ini memungkinkan untuk melahirkan bayi dengan perineum tetap utuh.Pijat perineum sangat mempengaruhi terjadinya robekan jalan lahir. Oleh karena itu, ibu hamil disarankan untuk melakukan pijat perineum pada 6 minggu akhir kehamilan, semakin sering dilakukan maka hasilnya akan semakin baik. Tidak hanya itu, mutu pelayanan yang ada di masyarakat khususnya pada pelayanan dasar seperti di posyandu atau puskesmas untuk dapat lebih meningkatkan keterampilan tenaga kesehatan saat memberikan konseling kehamilan, dan mengajarkan teknik pijat perineum sehingga dapat menurunkan angka kejadian robekan jalan lahir saat persalinan.

Peregangan pada perineum saat persalinan bisa mengakibatkan perubahan yang positif apabila perineum elastis, fleksible dan lentur maka kejadian ruptur perineum dapat diminimalisir atau tidak terjadi ruptur perineum sama sekali (perineum utuh) dan perubahan yang negatif apabila perineum tidak elastis, fleksible dan lentur maka regangan pada perineum akan mengakibatkan terjadi ruptur perineum. Maka salah satu cara yang dilakukan untuk menghindari terjadinya ruptur perineum dengan melakukan pemijatan perineum.

\section{SIMPULAN DAN SARAN}

Berdasarkan hasil penelitian yang telah dilakukan maka diambil kesimpulan bahwa : Hasil penelitian ini menunjukan bahwa dari 33 responden yang ada di Klinik Pratama Ratna Komala yang melakukan pijat perineum frekuensi $\geq 8$ sebanyak 17 responden dan sisanya yang tidak melakukan pijat perineum frekuensinya $\leq 8$ sebanyak 16 responden dengan alasan dari responden yang tidak melakukan dikarenakan males dan tidak merasakan nyaman melakukan pijat perineum. Hasil penelitian ini bahwa dari 33 responden yang tidak ruptur perineum sebanyak 22 responden dikarenakan perineum yang elastis dan ibu bersalin melakukan pijat perineum sebanyak $\geq 8$ frekuensi. Hasilnya penelitian ini menujukan bahwa terdapat hubungan Penerapan Pijat Perineum Untuk Mengurangi Ruptur Perineum Saat Persalinan hal ini dapat dilihat dari hasil penelitian nilai $p=0,002(\mathrm{p}<0,05)$.

Diharapkan ibu hamil yang menjelang persalinan mengkuti kelas anenatal penerapan pijat perineum agar dapat proses persalinan dapat berjalan sesuai dengan keadaaan atau masih kondisi baik, dan menguraingi terjadinya rupture perineum atau episiotomy. Diharapkan pada peneliti selanjutnya agar dapat meneliti responden yang sejenis untuk mendapatkan hasil peneliti yang optimal. 


\section{DAFTAR PUSTAKA}

Anggraini, Y., Kebidanan, J., \& Tanjungkarang, P. (n.d.). Pada Ibu Bersalin Primipara Di Bpm Kecamatan Metro, 155159.https://ejurnal.poltekkestjk.ac.id/index.p $\mathrm{hp} / \mathrm{JK} / \mathrm{rt} /$ printerFriendly/99/0. Diaskes 02 April 2018.

Aprilia, Y. (2010). Hipnostetri: Rileks, Nyaman Dan Aman Saat Hamil \& Melahirkan (Gagas Medi). Jakarta.

Arifia, M. (2015). Pijat Perineum Untuk Bebas Robekan Saat Persalinan. Jakarta. http://www.babyorchestra.wordpress.com. Diaskes 02 Mei 2018.

Depkes RI (2014). Depertemen Kesehatan Republik Indonesia. Asuhan Persalinan Normal (JNPK-KR). Jakarta

Depkes R.I (2016). Sistem Kesehatan Nasional. Jakarta.

Hadiningsih, T. (2014). Buku Saku Manajemen Unit Persalinan (EGC). Jakarta.

Kementrian Kesehatan Republik Indonesia.(2016). Profil Kesehatan Indonesia. Profil Kesehatan Provinsi Jawa Barat.

Kementrian Kesehatan Republik. Indonesia (Kemenkes RI).(2013) Riset Kesehatan Dasar (Riskesdas). Jakarta : Kemenkes RI.

Marmi. (2015). Asuhan Kebidanan Pada Persalinan (Pustaka Pe). Jakarta.

Masita, E. D. (2016). Pengaruh Pijat Perineum Terhadap Tingkat Kecemasan Pada Ibu Hamil Primigravida Trimester III, 4, 711.http://journal.unusa.ac.id/index.php/jhs/arti cle/view/77/69.

Notoatmojo, S. (2014). Metedologi Penelitian Kesehatan (Rineka Cip). Jakarta.

Pamungkas, A. R. (2017). Metodologi Riset Keperawatan (Trans Info). Jakarta.

Prawiroharjo, S. (2014). Ilmu Kebidanan Sarwono Prawiro Hardjo (PT Bina Pu). Jakarta.

Rukiyah, A. Y. (2014). Asuhan Kebidanan II (
Pesalinan) (Trans Info). Jakarta.

Sari, P. (2014). Asuhan Kebidanan Persalinan (Intranatal Care) (Trans Info). Jakarta.

Savitri, W., \& Yusefni, E. (2014). Artikel Penelitian Pengaruh Pemijatan Perineum pada Primigravida terhadap Kejadian Ruptur Perineum saat Persalinan di Bidan Praktek Mandiri di Kota Bengkulu Tahun 2014, 4(1), 8388.http://jurnal.fk.unand.ac.id/index.php/jk a/article/view/204. Diaskes 05 mei 2018

Suhartati, S., Kahfi, R. Al, Kebidanan, A., Mulia, S., \& Perineum, P. (2016). Banjarmasin.

Tando, M. N. (2016). Asuhan Kebidanan Persalinan Dan Bayi Baru Lahir (In Medika). Jakarta.

Turlina, L., \& Ummah, F. (2015). Perineal Massage and Lateral Position, (2014).Retrievedfromhttp://stikesmuhla.ac.id/ wpcontent/uploads/jurnalsurya/NoXX/26-35 Lilin Turlina S. SiT., M. Kes_artikel.pdf. Diaskes 23 mei 2018.

Walyani, E.(2015). Asuhan Kebidanan Pada Persalinan (Pustaka). Yogyakarta 